\title{
Integration of Ethnic Minority Cultural Moral Education in Ethnic Minority Areas - Taking the Mongolian Culture as an Example
}

\author{
Lijun Yang* \\ School of Politics and Law, Baotou Normal University, Baotou 014030, Inner Mongolia, China \\ *Corresponding author: Lijun Yang, 115474396@qq.com
}

\begin{abstract}
The traditional culture of ethnic minorities embodies the spiritual pursuit of unique national value. It can be used as a valuable moral education resource and is of great significance to improve the effectiveness of moral education in colleges and universities in ethnic areas. At present, China has not paid enough attention to the development and utilization of moral education resources of the ethnic minority traditional culture, nor has it established and improved the relevant development and utilization mechanism. Taking the moral education spirit of the traditional Mongolian culture as an example, this paper analyzes its moral education value, points out the existing problems of moral education in colleges and universities in ethnic areas, as well as suggests strategies for the integration of moral education resources of ethnic minority traditional culture with the moral education in colleges and universities in ethnic areas.
\end{abstract}

Keywords: National culture; Moral education resources; Moral education in colleges and universities

Publication date: August 2021; Online publication: August 30, 2021

\section{Introduction}

Culture is the sum of a series of precipitates accumulated by people that share certain common characteristics for a long time, such as knowledge, belief, values, religion, concept of time, spatial relationship, cosmology, and so on. It can be seen that beliefs and values constitute an important part of culture. Moral education, which is inevitably affected by social culture, is an important practical aspect to cultivate people's beliefs, shape their values, and stimulate moral cultivation. Each nation has its own unique history and culture. These unique historical memories and cultural genes shape the unique spiritual characteristics of each group. How to fully tap moral education resources from the traditional culture of ethnic minorities, consciously make use of its moral education value, innovate the ways and enrich the content of moral education, as well as improve the pertinence and effectiveness of moral education is the common issue faced by colleges and universities in ethnic areas ${ }^{[1]}$.

\section{Moral education resources of the Mongolian culture and its moral education value}

The spirit of a nation often reflects the inheritance and accumulation of its history and culture. Inner Mongolia has always been a multi-ethnic region. On this vast land, people from all ethnic groups have made great achievements in developing and creating Inner Mongolia's long history and splendid culture. In this article, Mongolian traditional culture is used as an example. Mongolian culture is the general term for material and spiritual wealth with national and regional characteristics that adapt to the long-term nomadic way of production of the Mongolian people. There are well-known symbols of material culture, such as Obo, Matouqin, and yurt, in addition to many grassland cultures that encourage people to pursue the 
harmonious coexistence of nature. The spirit of the Mongolian horse that inspires people to bravely move forward and the spiritual culture of traditional ethics, such as respecting the old and loving the young, honesty, and trustworthiness, are valuable moral education resources.

\subsection{Excavate the spirit of moral education from grassland cultures and enhance college students' national cultural identity}

Grassland culture refers to the culture that is jointly created by the nationalities, tribes, and ancestors in the grassland area. It includes people's way of life, mode of production, customs, ideas, social systems, religious beliefs, literature, and art in the grassland area. The core spirit of grassland culture advocates nature and the unity of heaven and man; it also abides by faith and pursue the harmonious coexistence between man and nature. This powerful spiritual force drives the moral education spirit into moral education at colleges and universities, such as ecological consciousness of reverence for nature, patriotic feelings of loyalty, heroic spirit of bravery, moral concept of abiding by faith, open and inclusive national mind, and so on. This spirit does not only enhance the recognition of the ethnic minority college students' own cultural values, but also promotes the dissemination and practice of this spirit ${ }^{[2]}$.

\subsection{Encouraging college students to strive for self-improvement with the spirit of the Mongolian horse}

Mongolia is known as the land of the horse; the Mongolian horses are the souls of the grasslands. They are not only connected with the blood of the Mongolian people, but also the hope and sustenance of the nation. The General Secretary, Xi, once said, "We hope that people from all walks of life would learn the spirit of the Mongolian horse when they start off their businesses while bearing hardships and withstanding hard work." After a long historical accumulation, the spirit of the Mongolian horse has become an important spiritual source and power for the people of all ethnic groups to strive for self-improvement and forge ahead. Especially for young students, who are in the struggling phase of life, they should learn from the spirit of the Mongolian horse to encourage themselves to work hard, strive for self-improvement, and overcome difficulties.

\subsection{Cultivate college students' personal moral cultivation with traditional Mongolian ethics and morality}

First of all, the respect for elders is a quality that is valued in the traditional Mongolian moral education. In addition, there are proverbs in respect to that, such as "gold and silver are easy to acquire, but parents are rare" and "living Buddha is not in the temple but at home; parents are the living Buddha." When talking to the elderly, young people need to listen respectfully before they can respond politely. Secondly, in the education of unity and mutual assistance, the classic story of Five Arrows Training, which is passed down from generation to generation, vividly and intuitively reveals to children about the significance of unity and mutual assistance. Thirdly, thrift is also an important part of traditional Mongolian ethics and moral education. There are also proverbs that remind people to be diligent, thrifty, and cherish the fruits of labor, such as "a grain of rice falling on the ground is a camel from the sky" and "if you accumulate a needle, you can hit an axe; save your axe and you will build a temple." Finally, Mongolian people also value the moral character of honesty and trustworthiness; they regard honesty and trustworthiness as the foundation of settling down. Loyalty has become the highest standard for Mongolian people to measure harmonious and friendly relations. There are also proverbs such as "a lost horse can be recovered, but what has been said cannot be taken back" to teach children to be honest and trustworthy. Every generation of the Mongolian people have been nurtured in this cultural and moral environment, in which the traditional ethics of 
respecting the elderly, unity and mutual assistance, diligence and thrift, as well as honesty and trustworthiness have been gradually formed. If they can be made full use as moral education resources in colleges and universities, it is then possible to improve and standardize college students' traditional moral concepts as well as their personal moral cultivation.

\section{Bottlenecks of moral education in colleges and universities in ethnic minority areas}

\subsection{Poor awareness of the development and utilization of moral education resources from ethnic minority culture}

Professor Lu Jie, a Chinese scholar, once said that the current research on moral education in China only follows the Chinese cultural model. Whether it is the determination of moral objectives, the selection of content, the use of methods, or the grasp of students' moral psychological structure, it is still based on the Chinese culture. It can be seen that in the design of moral education contents, moral education resources from ethnic minority cultures have not been fully reflected or excavated. Although there were many research results on ethnic minority cultures in recent years, their integration into moral education is lacking. In addition, the development and utilization of ethnic minority cultures and moral education resources are inadequate. It is impossible for a nation to establish a new culture in a desert, and it is impossible for a person to improve himself without a growing culture. What college students can recognize the most and accept is their own local culture. If the traditional culture of ethnic minorities in the content of moral education is scarce and separated from the reality of ethnic minority areas, it is difficult to improve students' moral resonance in ethnic minority areas, resulting in an unsatisfactory effect of moral education ${ }^{[3]}$.

\subsection{Failure of moral education curriculum to fully meet the actual moral education needs of ethnic minority college students}

At present, the main channel of moral education in colleges and universities in China is still through ideological and political theory courses. According to a survey of the current moral education in colleges and universities, ethnic minority college students generally lack a sense of value identity, which does not only weaken their willingness to learn, but also the correct understanding of their own traditional culture as they are in long-term contact with the mainstream mass culture. Many students are not even able to answer when they are asked certain common-sense questions about their own nation. Although the moral education curriculum in China keeps pace with the development of the society, the homogenization of the moral education curriculum in the same period is serious, in which it does not take into account the particularity of the moral education in ethnic areas or fit well with the actual moral education needs of the students in ethnic areas, resulting in difficulties for students to accept and affecting the effectiveness of moral education.

\subsection{Lacking cognition of moral education among ethnic minority college students under moral conflict}

Due to the particularity of geographical location and the uniqueness of historical development, ethnic minority areas have formed unique geopolitics and geo-culture, which highlight the particularity and complexity of moral education in colleges and universities in ethnic minority areas. For ethnic minority college students, they are not only influenced by foreign culture, mainstream culture, and subculture, but also faced with the conflict and contradiction among national traditional culture, mainstream social culture, and western culture. These would inevitably lead to the confusion of values and hinder the formation of healthy values. At present, this prominent moral conflict in ethnic minority areas has not attracted enough attention from relevant departments, and there is also a lack of valuable experience and research. 
4. Ways to integrate the traditional culture of ethnic minorities into the moral education in colleges and universities in ethnic areas

\subsection{Raising awareness of the development and utilization of moral education resources from ethnic minority culture}

Thought determines action. Therefore, colleges and universities in ethnic areas should first establish the awareness of the development and utilization of moral education resources from ethnic minority culture. In addition to that, they should not only fully realize the widespread existence of the former, but also realize the value of rational development and utilization of rich moral education resources from ethnic minority culture. The development and utilization of excellent moral education resources from ethnic minority culture do not only improve the moral identity of ethnic minority college students, but also improve their moral resonance as well as the effectiveness of moral education in colleges and universities in ethnic minority areas, and eventually promote a harmonious, stable, and sustainable development of the society in ethnic minority areas.

\subsection{Relying on the moral education resources of national culture, compile local moral education books}

In order to better enable students to learn and understand the rich moral thoughts and cultural resources of all ethnic groups while inheriting excellent cultural and moral education resources, colleges and universities in ethnic areas can designate relevant experts and teachers to excavate and sort out the cultural and moral education resources of all ethnic groups as well as compile popular moral education books. It is important to allow college students to understand and experience excellent cultural moral education resources of their own nation, as well as the process of ideological perception, inner identity, and action time.

\section{Strengthening teachers' reserve of national cultural knowledge and develop moral education courses with local characteristics}

Curriculum is an effective way to achieve the purpose of education. In developing the curriculum, using traditional national culture to develop moral education curriculum with national characteristics is an important issue for college teachers in ethnic areas. Due to different nationalities and professional fields, most college teachers believe that the development and protection of ethnic minority cultural and moral education resources are the responsibilities of ethnic minority teachers and ideological and political teachers, in which these measures have nothing to do with them. If teachers want to teach and educate people, it is necessary to first improve the awareness of developing and utilizing the excellent national cultural and moral education resources in the region; secondly, there is a need to continuously improve the national cultural knowledge reserve; third, the excellent national cultural and moral education resources in the region should be fully utilized to develop a moral education curriculum with local characteristics, and finally form the ideological and political course as the core. The moral education curriculum system that is supported by local characteristics provides an "Inner Mongolia plan" for the realization of three complete education in colleges and universities in ethnic areas.

\section{Funding}

This study was supported by the 2021 Scientific Research Project of Colleges and Universities in Inner Mongolia Autonomous Region: Research on the Construction Path of Moral Education Community in Colleges and Universities in Ethnic Minority Areas in the New Era - Taking Inner Mongolia as an Example (Phased achievements of njsy21033). 


\section{Disclosure statement}

The author declares that there is no conflict of interest.

\section{References}

[1] Samovar LA, Porter RE, McDaniel ER, 2000, Communication between Cultures, Peking University Press, Beijing, 36.

[2] Wang H, Cheli M, Tana, 2020, Research on the New Realm of Mongolian Horse Spirit and the Core Concept of Grassland Culture. Research on Local Culture, (4).

[3] Liu W, Tang K, 2008, Thoughts on Using Local Cultural and Educational Resources for Reference in the Course of "Ideological and Moral Cultivation and Legal Basis". Journal of Baise University, (5). 